\title{
Corrigendum
}

\section{Gastro-intestinal toxicity related to bone marrow transplantation: disruption of the intestinal barrier precedes clinical findings.}

\author{
JE Johansson and T Ekman
}

Bone Marrow Transplantation 1997; 19: 921-925

Since publication of the above paper, the author has identified errors in the following data.

Table $3 \quad{ }^{51} \mathrm{Cr}$-EDTA resorption (\% $\%$ s.d.) on different measurement days. $P$ values for comparisons with baseline

\begin{tabular}{lccc}
\hline Day & $n$ & ${ }^{5 I}$ Cr-EDTA & $P$ \\
\hline Baseline & 25 & $1.9 \pm 0.9$ & - \\
Cond +2 & 7 & $2.7 \pm 0.7$ & $<0.05$ \\
1 & 6 & $2.9 \pm 1.3$ & $<0.05$ \\
4 & 18 & $4.7 \pm 3.8$ & $<0.0005$ \\
7 & 20 & $4.0 \pm 2.7$ & $<0.005$ \\
10 & 16 & $3.1 \pm 3.0$ & NS \\
14 & 15 & $2.4 \pm 1.9$ & NS \\
\hline
\end{tabular}

Baseline $=$ before the start of the conditioning treatment; Cond $+2=2$ days after the start of the conditioning treatment.

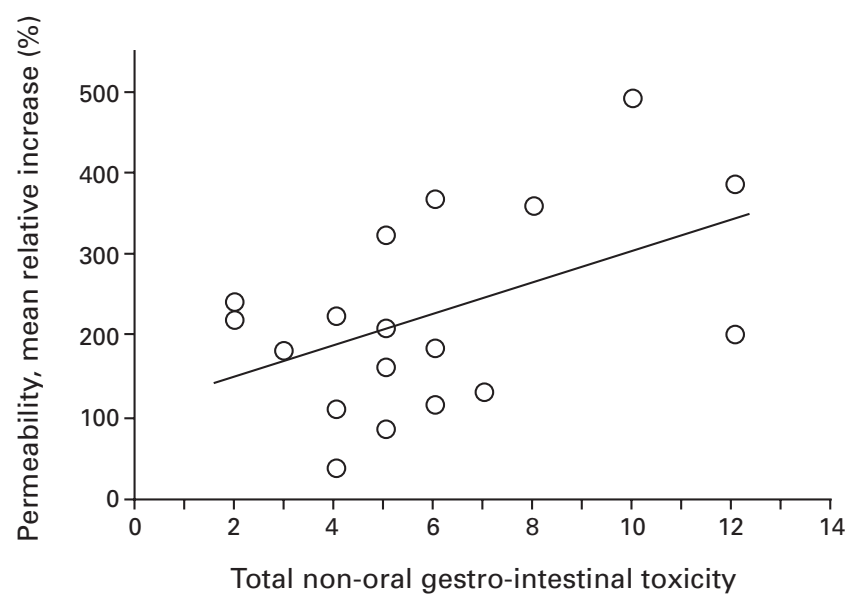

Figure 1 Correlation between the cumulative intestinal (non-oral) toxicity (the sum of the toxicity grades on day $4,7,10$ and 14) in the 14 day post-transplant period and the mean relative increase in permeability for each patient. $r=0.48, P<0.05, n=18$ (linear regression).

Table 4 Comparisons between observations of gastro-intestinal and oral toxicity requiring therapy (grades 3 and 4 according to the WHO) and not (grades 0,1 and 2$)$, with respect to permeability ( $\% \pm$ s.d.) for all 25 patients

\begin{tabular}{|c|c|c|c|c|c|c|}
\hline \multirow[t]{2}{*}{ Toxicity } & \multicolumn{3}{|c|}{ Gastro-intestinal } & \multicolumn{3}{|c|}{ Oral } \\
\hline & $C r-E D T A$ & $n^{a}$ & $P$ & $C r-E D T A$ & $n$ & $P$ \\
\hline $\begin{array}{l}\text { Not requiring therapy } \\
\text { Requiring therapy }\end{array}$ & $\begin{array}{l}3.2 \pm 2.4 \\
5.5 \pm 3.7\end{array}$ & $\begin{array}{l}68^{\mathrm{b}} \\
14\end{array}$ & $<0.05$ & $\begin{array}{l}3.3 \pm 2.6 \\
4.7 \pm 3.5\end{array}$ & $\begin{array}{l}67^{\mathrm{b}} \\
15\end{array}$ & NS \\
\hline
\end{tabular}

${ }^{a}$ Number of observations.

${ }^{\mathrm{b}}$ All baseline values are excluded. 